\title{
The Influence Of Media On Attitudinal And Behavioral Changes: Acceptance Of Culture And Products
}

Rahmiati Lita, KDI School of Public Policy and Management, Korea Yoon C. Cho, KDI School of Public Policy and Management, Korea

\begin{abstract}
Culture affects every part of our lives, every day, from birth to death, and everything in between (Cateora, Gilly, and Graham 2011). This study discusses the way in which customers' acceptance of cultures and products has been greatly affected by the media. This study also investigates how customers' acceptance leads to attitudinal and behavioral changes. In particular, this study measures the impact of a cultural wave to examine the attitudinal and behavioral changes it causes. This study explores the causes that affect the willingness of people to change their behavior after exposure to the media. In particular, this study investigates 1) how a cultural wave influences product and cultural awareness, 2) the relationship between perceptions of a cultural wave and people's attitudes and behavior, and 3) the relationship between the strength of people's attitudes toward acculturation and changes in attitude and behavior. By applying various statistical analyses, this study identifies managerial and theoretical implications.
\end{abstract}

Keywords: Media; Culture; Product; Attitude; Behavior

\section{INTRODUCTION}

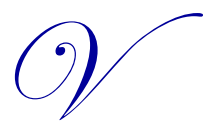

arious studies have investigated the impact of television viewing on the beliefs, opinions, attitude changes, and behavior of viewers (Nabi and Sulivan, 2001). Potter (1988) stated that the perceived reality of a media presentation may influence mental processes, attitudes, beliefs, and behaviors (Shapiro and Chock, 2003). Prior studies explained the influence of the media on attitudinal and behavioral changes by applying theories of media effects, such as the theory of reasoned action (Fishbein and Ajzen, 1975; Nabi and Sulivan, 2001) and cultivation theory (Gerbnber, 1969; Shrum and Bischak, 2001).

Media-mediated culture (Lee, 2011), including the current power of Social Networking Sites (SNS), has greatly affected the acceptance of the cultures and products shown in the media. The impact of this media-mediated environment has created cultures such as the Korean wave (called hallyu in Korean), which is an extraordinary form of pop culture that has been introduced through the media as a form of commercial nationalism (Lee, 2011). Consequently, regional cultures have become world trends, which are reflected in cultural waves (Lee, 2011). A previous study by Ravina (2010) explored the phenomenon of the Korean wave, or hallyu - a new culture within the international scene that started in East Asia in the 1990s and has more recently spread to the United States, Latin America, the Middle East, and parts of Europe. Furthermore, Lee (2011) suggested that the impact of the media permeates popular culture and also provides a measure of a positive lifestyle.

By considering the effects of the media on attitudinal and behavioral changes, this study attempts to analyze the acceptance of cultures and products. In particular, this paper investigates 1) the causes that affect people's willingness to change their behavior via media, 2) how a cultural wave influences product awareness and culture, 3) the relationship between perceptions of the Korean wave and people's attitudes, and 4) the relationship between the strength of the people's attitudes toward acculturation and changes in attitude and behavior. 


\section{LITERATURE REVIEW}

The media play a significant role by influencing attitudes and behavioral changes based on how audiences accept programs and are willing to change their behavior. Nabi and Sullivan (2001) attempted to predict consumer behavior by addressing media effects, such as cues, along with the concepts of salient beliefs and attitudes. Jeffres, Atkin, and Neuendorf (2001) also explored the relationship between media use, such as television viewing, and measures purporting to distinguish TV programs from reality. Attitudes and behavioral changes can also be explained through elements such as 1) how to accept a new behavior, 2) how to reject a potentially undesirable behavior, 3) how to modify a current behavior, and 4) how to abandon an old undesirable one (Kotler and Lee, 2008).

This study posits that the media have affected various factors and issues, including national branding, overall image, acceptance of cultures and countries, and even relationships among countries. Lee (2011) also stated that media can, and do, influence societies, cultures, and identities (Peart, 2010) by addressing relationships among countries, national branding through cultures, and cultural imperialism and backlash. The impact of the media is also explained by socio-cultural, experiential, symbolic, and ideological aspects of consumption as the media portray multiple aspects of symbolic images of culture and country.

This study specifically investigates the impact of the media on the export of the Korean wave to other cultures. The Korean wave, consisting of two forms of media - television series and pop music (Ravina, 2010) indicates the development of the recognition of South Korean culture (hallyu) around the world. This terminology was created by Beijing journalists in 1997, at which time Korean entertainment and culture became increasingly popular in China (Lee, 2011). The Korean wave was created based on popular culture as a societal and cultural movement, and today it has become a comprehensive approach to and enthusiastic embracing of Korean culture as a whole (Kang, 2011). Therefore, the Korean wave is now utilized as a symbol of the identity of Korean culture in a globalized world and plays an important function in producing a new cultural wave and facilitating active interchanges of popular culture among neighboring Asian countries (Kang, 2011).

According to Mariani (2008), the Korean wave has caused increasing consumption of Korean goods and products and increased travel to South Korea. This phenomenon has spread throughout the world, especially among teenagers, who especially appreciate South Korean popular culture, such as TV drama, music, and games, and who embrace several aspects of Korea, including its culture, products, and people (Mariani, 2008). The Korean wave has become a general term that describes the boom of interest in South Korean pop culture (Ko, 2010). Some countries, such as China and Vietnam, are importing more South Korean products, such as cosmetics, fashion goods, and electronics. This phenomenon is also spreading to other regions, such as Indonesia.

This study attempts to analyze the acceptance of Korean culture and products through the effects of hallyu. To achieve the purpose of the study, this study primarily investigates some stimuli that affect the acceptance of the culture and products. In particular, this paper examines 1) causes that affect the willingness of people to change their behavior, 2) effects of the cultural wave on product awareness and culture, and 3) effects of the relationship between perception of the cultural wave and attitudinal and behavioral changes.

\section{THEORETICAL BACKGROUNDS}

The impacts of the media on different cultures are explained by various theories. The theory of reasoned action discusses causes that affect behavior and has been applied by various researchers (Fishbein and Ajzen, 1975; Nabi and Sulivan, 2001). The main constructs of the theory of reasoned action are behavior, intention, personal attitude, and subjective norms (Fishbein and Ajzen, 1975; Ajzen and Fishbein, 1980; Wang, 2005).

Cultivation theory, proposed by Gerbner (1969) also supports the relationship between media and culture, and as the theory asserts, it's focus changes according to how the media influence a person's perceptions of his or her own social reality (Ewoldsen, Davies, and Ewoldsen, 2004). According to Gerbner, cultivation theory, in particular, arose from concern about the potential effect that television programming might have on people's worldviews and their related behavioral responses (Nabi and Sulivan, 2001). Nabi and Sulivan (2001) also developed cultivation theory as a theory of media effects, stating that television is the most common source of socialization and everyday information in our society and that most television programming shares similar 
storytelling features (Gerbner, 1969; Gerbner, Gross, Morgan, \& Signorielli, 1994). Nabi and Sulivan (2001) stated that cultivation theory determined that television viewing influences beliefs and opinions about the real world. Furthermore, Morgan and Shanahan (2010) addressed cultural indicators, such as institutional process analysis, which involves investigation of the institution that produces the media content - message system analysis, which examines the structure and pattern in media content, and cultivation analysis, which is defined as the study of the relationship among the institutional process, message system, public assumptions, images, and policies.

Manrai and Manrai (2011) presented four categories of influence on consumer behavior; namely, 1) cultural influences, 2) social components, 3) personal components, and 4) psychological components; the latter three are consequences of culture. Furthermore, culture itself is divided into two basic elements; namely, material (food, clothes, art, etc.) and abstract elements (values, customs, behavior, etc.) (Manrai and Manrai, 2011) Consumer Culture Theory also refers to a family of theoretical perspectives that addresses the dynamic relationships between consumer actions, the marketplace, and cultural meanings (Arnould and Thompson, 2005).

\section{HYPOTHESES DEVELOPMENT}

A cultural wave, as defined by Mariani (2008), causes the increased consumption of products of, increasing interests in the culture of, and an increase in travel to the country of origin, as shown in the media. This phenomenon has drawn the world, especially teenagers, to appreciate certain aspects of popular culture, such as TV dramas, music, and games, and to embrace everything about the country and culture, including its products and people (Mariani, 2008). Many people change their preferences due to the media. In particular, this study hypothesizes that the spreading of the cultural wave has also had a huge effect in changing attitudes and behavior. Therefore, this study proposes that a movement, particularly a cultural wave, influences people's perceptions and preferences. Based on this consideration, this study examines the affective and cognitive dimensions of the media and the likelihood of people to change their preferences as a result. As shown in Figure 1, this study proposes four major causes of the cultural wave that may produce a willingness to change attitudes and behavior. Moreover, this study proposes that perceptions of actors and actresses and pop/soundtracks may have additional effects on consumers.

Figure 1: The Proposed Model Describing the Impacts of Cultural Wave on Attitudes and Behavior

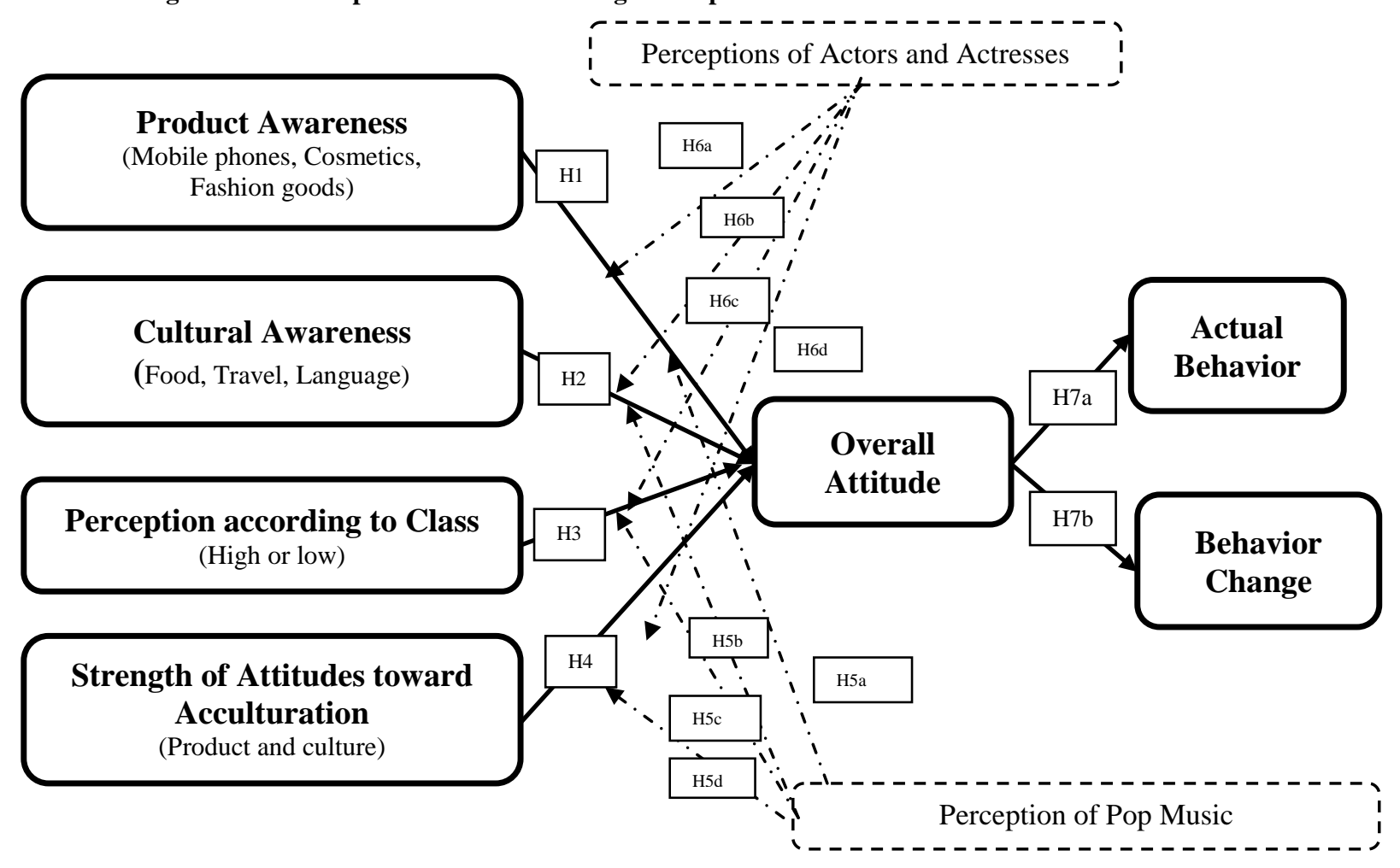




\section{The Effects of Product Awareness on Overall Attitudes}

The cultural wave boom has an impact on the building up and changing of companies' and products' images. Various companies have provided sponsorship by lending products to be used in dramas - usually products such as mobile phones used by the main actor/actress. Product placement, as a substitute for television commercials, has been widely used and explained as one of the trends that are altering the media landscape (Belch and Belch, 2007). Chan (2012) stated that product placement is gaining more attention in the marketing domain due to media fragmentation and increasing consumer sophistication. Gregorio and Sung (2010) addressed the impact of product placement to the attitudes and related behavior in a theoretically grounded manner. Gregorio and Sung (2010) also stated that investigations of attitudes toward product placement have revealed generally positive perceptions of the practice overall.

This study, in particular, has addressed the effects of product placement when it is used in soap operas aired in the international market. However, customers' acceptance of international brands used in soap operas has elicited less attention in this study. Practical reports have found that the market share of a mobile phone brand increases due to the impact of the soap opera and other media (Naripan, 2011). This phenomenon of media impact affects categories that include fashion, music, and film and gives a higher profile to placed products, like mobile phones, cosmetics, and clothes. Accordingly, this study hypothesizes that perceptions of products placed in the media are positively related to the willingness to purchase products that are associated with or made in the correponding country.

H1: The perception of awareness of products is positively related to the overall attitudes toward the products placed in the media.

\section{The Effects of Culture Awareness on Overall Attitudes}

Prior studies have shown that culture influences the way humans select, interpret, process, and use information (Triandis, 1994). The studied cultural elements included patterns of dress, specific technological innovations, methods of getting food, economic activities, patterns of social interaction and child rearing, ways to resolve conflict, beliefs and behaviors, and patterns of communication (Triandis, 1994). This study examines whether the media presentation of the cultural wave significantly affects and offers the development of cultural awareness of such elements as food, language, and nation. Nopiyanti (2011) stated that people start searching, knowing, and liking culturally symbolic items, such as food, and enjoy related events. For example, one soap opera fan said "from the way they talk, to their food, they are close to culture" (Mariani, 2008). Another effect is that people become interested in learning the language demonstrated in the media.

Theoretically, how customers perceive information, such as culture through the media, has been explained by cognitive process models. Shrum (2009) stated that the development of cognitive process models explain media effects. Studies suggest that social cognition can best be described as an orientation toward the cognitive processes that occur in social situations (Shrum, 2009; Reeves, Chaffee, \& Tims, 1982). The way in which awareness of cultures among audiences is affected by the media has been explained by prior studies that posit social cognition research and theories that focus on a "black box" that operates between a stimulus (e.g., information) and a response (e.g., judgment) (Wyer, 1980; Shrum, 2009). Accordingly, this study hypothesizes that the stimulus (i.e., the cultural wave) via media affects the acceptance of the culture, which is response.

H2: The perception of the cultural wave, as a result of the media, is positively related to overall attitudes toward the adoption of the culture.

The Effects of Perception of Suitability of the Cultural Wave for Respondents' Social Class on Overall Attitudes

Some works of research have focused on the power of Hollywood movies and music in diverse societies. The effects have varied based on the cultural environments, particularly environments where there is perception of class, such as Indonesia. Heryanto (2010) stated that there is clearly a class bias in Indonesia, where the middle class 
has not seriously absorbed Hollywood movies and music, but more easily absorbs other cultures, such as East Asian pop culture. The middle class perceives East Asian pop culture as an alternative expression of modernity and pop culture to those produced in the major centers of entertainment industry in the West, and many urban middle-class youth indulge in the pleasure of watching East Asian television images and narratives of active characters enjoying a materially comfortable and elegant life style (Heryanto, 2010). Accordingly, the focus of the following hypothesis is a measure of the effects of the cultural wave on willingness to change among those in a class-conscious society.

H3: The perception of higher social class, who has better images of the cultural wave, is positively related to overall attitude.

\section{The Effects of Strength of Attitude toward Acculturation on Overall Attitudes}

The spreading of a cultural wave has a huge influence on attitude and behavior; however, the rates of acceptance of people in such accepting areas are different because acculturation to a new society occurs at different rates and different levels. Some accept a new culture relatively quickly whereas others require more time (Seo, Phillips, Jang, and Kim, 2012).

Generally, acculturation is a social cultural process in which members of one cultural group adopt the beliefs and behaviors of another group (Class, Castro, Ramirez, 2011). According to Lee and Tse (1994), acculturation is a cultural exchange that is initiated by the conjunction of two or more autonomous systems. It can be induced by environmental or statistical changes due to the collision between two cultures or can be delayed by internal adaptation or the acceptance of heterogeneous traits or forms. Therefore, this study hypothesizes regarding the relationship between acculturation and the acceptance of products and culture as an impact of the Korean wave.

H4: The perception of higher views of acculturation is positively related to overall attitude.

\section{The Effects of Perception of Pop Music and Actors/Actresses}

The effects of the cultural wave have spread into many areas, such as the growth and acceptance of songs or soundtracks that are embedded in drama or movies. There is an emerging trend of recognition of songs and singers. In many countries, this has become integral to the daily entertainment program. Moreover, films and dramas are watched daily on big and small screens, in movie houses or privately on television with regular programs or legal or pirated DVDs (Huat, 2010). This indicates that audiences are getting familiar with the lifestyle of the new culture. As a consequence, audiences seek information about the actors' and actresses' lives, try to follow the lifestyles of their idols, and end up collecting merchandise suggestive of their idols. Therefore, this study hypothesizes the following relationships between perception of pop/soundtracks and affection for the actors and actresses who take part.

H5a: The perception of products associated with the cultural wave and the willingness to change one's attitude are affected positively by perceptions of pop/soundtracks.

H5b: The perception of culture associated with the cultural wave and the willingness to change one's attitude are affected positively by perceptions of pop/soundtracks.

H5c: The perception of the suitability of the cultural wave for respondents' social class and the willingness to change one's attitude are affected positively by perceptions of pop/soundtracks.

H5d: The strength of attitude toward acculturation to the cultural wave and the willingness to change one's attitude are affected positively by perceptions of music/soundtracks.

H6a: The perception of products associated with the cultural wave and the willingness to change one's attitude are affected positively by perceptions of actors and actresses. 
H6b: The perception of culture associated with the cultural wave and the willingness to change one's attitude are affected positively by perception of actors and actresses.

H6c: The perception of suitability of the cultural wave for respondents' social class and the willingness to change one's attitude are affected positively by perception of actors and actresses.

H6d: The strength of attitude toward acculturation to the cultural wave and the willingness to change one's attitude are affected positively by perceptions of actors and actresses.

\section{The Effectiveness of Overall Attitudes on Actual Behavior and Behavior Change}

According to the American Marketing Association, the definition of consumer behavior is the dynamic interaction of affect, cognition, and behavior in an environment in which human beings exchange aspects of their lives (Mooij, 2004). Triandis (1994) stated that ecology applied to where people live and how human life is affected by various physical environments affect culture and also social behavior. Cultivation theory also explains the relationship between audience perception of media products and people's consequent behaviors. Cultivation theory deals with how the mass media affect an individual's construction of social reality (Kim, Singhal, Hanaki, Dunn, \& Han, 2009). Also, social action theory provides a theoretical background for considering the relationship between audience perception and behavioral consequences. Based on these considerations, this study posits that the media plays a role in changing attitudes and behavior by different degrees depending on how audience perceive and are involved in it. This paper tries to measure whether there is a relationship between audiences' perception and their overall attitudes and consequences of their behavior.

H7a: There is a positive relationship between overall attitude and actual behavior.

H7b: There is a positive relationship between overall attitude and behavioral change.

\section{METHODOLOGY}

This study examined the impact of the cultural wave, in particular on the acceptance of Korean culture and products and on attitudes and behavior. In particular, this study measures the impacts of product and cultural awareness, perception of the suitability of the cultural wave for respondents' social class, the strength of attitudes and acculturation to culture, and behavior. In order to measure effectiveness, this study investigated the links between the causes of the cultural wave and attitudes in addition to links between actual and potential behavior and the perceptions of actors/actresses and pop/soundtracks. This study collected data via both online and offline methods. For online data collection, this study used the system powered by Qualtrics and applied stratified sampling during the data collection process, based on the percentage of customers according to their gender, age, education, income, field of work, and geographical location of residency.

A survey questionnaire consists of both multiple choices and multi-item scales. In order to measure each of the constructs, this study used multi-item scales, including a Likert scale format. This study applied a 5-point scale with higher numbers representing higher level of feelings, such as "strongly agree" (Cho, 2011). This study, in particular, measured the effects of the Korean wave on the Indonesian people. The questionnaire was divided into four sections; namely, 1) understanding of the Korean wave, 2) attitudes and behavior toward the Korean wave, 3) perceptions and understanding of the Korean wave, and 4) demographic information. This was intended to test the dependent variables (overall attitudes and behavior) and independent variables (product awareness, cultural awareness, perception of suitability for respondents' social class, and strength of attitudes toward acculturation). After the review and a pilot study, the researchers selected approximately 39 major items to represent the major constructs, such as factors that affect overall attitude and behaviors.

In order to measure the overall attitude toward the Korean wave, this study examined both affective and cognitive components. The affective component is the component of attitude that reflects one's general feeling or emotion toward an object (Zikmund, 2010). Questions, in terms of this component, were asked to determine respondents' likes or preferences concerning Korean products and culture as a result of the Korean wave. The 
respondents were asked how likely they were to use Korean products or learn about Korean culture to determine their attitudes toward the Korean wave. As a consequence, it could be seen that there were changes of behavior and attitude toward the Korean wave becoming more positive toward the acceptance of Korean products and culture. Behavior was assessed through a 5-point Likert scale in order to determine the respondents' likelihood of action or intention to perform some future action (Zikmund, 2010). Two kinds of behavior were measured - actual and potential behavior. Therefore, respondents were asked for their opinions, after purchasing Korean products or learning about Korean culture, to assess their actual behavior. Also, they were asked about their willingness to purchase Korean products or learn about Korean culture in the forthcoming days. The respondents were able to choose a range of answers from "definitely will not" to "definitely will."

Korean product and cultural awareness was measured using a cognitive component; that is, the component of attitude that represents one's awareness of and knowledge about an object (Zikmund, 2010). This component was used to determine the respondents' awareness of the Korean wave and its effect on their acceptance of Korean product and culture. The factors that were important in influencing them to purchase Korean products and to learn about Korean culture were determined through their answers on a 5-point Likert scale ranging from "very unimportant" to "very important." Perceptions of the suitability of Korean products and culture for respondents' social class were examined through questions posed to youth about the Korean wave. Respondents were asked to agree or disagree with the following statements:

1. "Having knowledge about Korea may boost my prestige."

2. "If I'm using a Korean product, I can be seen as an up-to-date person."

3. "I feel that the Korean products I purchase represent my social status and class."

These perceptions were also measured by asking respondents about the social acceptability of their decision-making about purchasing Korean products and learning about Korean culture. Questions on the variability and strength of attitudes toward acculturation were also included. The respondents were asked about their degree of agreement about Korean life and fashion style and similarity with Indonesian style. The degree of acceptance of Korean style was considered relevant to measure the strength of acculturation of youth toward another country's culture.

Perceptions of pop/soundtrack and Korean celebrities were assessed with a simple yes/no category scale in addition to the Likert scale. This scale, as explained by Cooper and Schindler (2008), offers two mutually exclusive response choices to each question. Respondents were given questionnaires exploring their understanding and perceptions about Korean drama, songs, and artists. They were also asked to specify how much they liked particular Korean artists by answering a question, on a 5-point scale ranging from very infrequently to very regularly, regarding how likely they were to follow information about Korean artists regularly.

Furthermore, the questionnaire was distributed to seven respondents in order to examine its validity. As a consequence, the questionnaire was revised based on suggestions from the respondents, and the irrelevant and vague questions were changed and adjusted to ensure understanding.

\section{RESULTS}

\section{Respondents Demographics}

The survey was distributed to 207 randomly selected people. The study collected data from Indonesia to measure the effects of the Korean cultural wave to answer the research questions. Of the 197 surveys distributed, 166 were returned, which represents a response rate of $80 \%$. About $80 \%$ of the respondents answered that they are familiar with the Korean wave. About $46.4 \%$ of the respondents said that they spend more than three hours/week enjoying Korean entertainment. 


\section{Demographics}

Of the 166 respondents, $79 \%$ were female and $21 \%$ were male. Their education levels were: 1) $0.6 \%$ had graduated from junior high school, 2) $44 \%$ had graduated from senior high school, 3) $46.4 \%$ had a Bachelor's degree, and 4) $8.4 \%$ had a Master's degree. The respondents belong to numerous age groups. Approximately $0.6 \%$ belonged to the younger-than-15 age group, $21.1 \%$ were in $16-20$ age group, $45.2 \%$ were between 21 and $25,19.9 \%$ were in the 26-30 age group, $8.4 \%$ were between 31 and 35, 2.4\% were in the $36-40$ age group, $0.6 \%$ were in the 41 45 age group, $0.6 \%$ were in the $46-50$ age group, and $1.2 \%$ were in the older-than-50 age group. Regarding their occupations, $1.2 \%$ of the respondents were unemployed, $59 \%$ were students, $31.9 \%$ were employees, and $6.6 \%$ were self-employed.

\section{Hypotheses Testing}

This research treated overall attitudes and behaviors as major variables, with product awareness, cultural awareness, perception of the suitability of the cultural wave for respondents' social class, and strength of attitudes toward acculturation as two-sided effect variables. To test the hypotheses, a regression analysis was applied to reveal relationships, such as 1) the correlation between the four independent variables and overall attitude and 2) the correlation between the four independent variables and actual behavior and willingness to change. Moreover, two other variables (i.e., perceptions of actors and actresses and perceptions of pop music) were assessed using ANCOVA to determine whether or not they affected people's overall attitudes.

The impact of the Korean wave on overall attitude was examined by using a multiple regression analysis with four independent variables, including product awareness, cultural awareness, perception of the suitability of the cultural wave for respondents' social class, and strength of attitudes toward acculturation with two dependent variables (overall attitudes and behavioral change). Table1 represents the results of the regression analyses of the effects of overall attitudes on actual behavior and behavior changes based on Figure 1. The results in Table 1 show that hypotheses $\mathrm{H} 1$ and 2 were accepted at the significance level of 0.01 , while hypotheses $\mathrm{H} 3$ and 4 were not accepted. The results of the ANOVA, in the case of purchase, found that the models were significant at the .01 level with an $F$-value of 21.274 .

Table 1: Summary of the Effects of Variables on Overall Attitudes

\begin{tabular}{|l|c|c|}
\hline Variables & Standardized Coefficient & .307 \\
\hline Product factor => Overall Attitudes & .327 & $3.420(* * *)$ \\
\hline Culture Factor => Overall Attitudes & .091 & $4.133(* * *)$ \\
\hline Class Factor=> Overall Attitudes & .121 & 1.027 \\
\hline Acculturation Factor => Overall Attitudes & 1.353 \\
\hline
\end{tabular}

*** Significant at the 0.01 level (2-tailed)

This study measures how overall attitudes affect actual behavior and cause behavior change. The results of the regression analyses show that overall attitudes affect actual behavior and cause behavior change. Table 2 provides the results which show that the effect of overall attitudes on actual behavior is significant at the 0.01 level. The results of ANOVA also find a significant $F$-value of 56.184 (significant at $0.01 \%$ ) with an $r$-square of 0.255 . The results of the effects of overall attitudes on the behavior change are also significant at $0.05 \%$. Therefore, hypotheses $7 \mathrm{a}$ and $\mathrm{b}$ are accepted.

Table 2: Summary of the Effects of Overall Attitudes on Actual Behavior Change

\begin{tabular}{|l|c|c|}
\hline Variables & Standardized Coefficient & \\
\hline Overall Attitudes => Actual Behavior & .505 & $7.496(* * *)$ \\
\hline Overall Attitudes => Behavior Change & .176 & $2.290(* *)$ \\
\hline$* * *$ Significant at the 0.01 level (2-tailed);** Significant at the 0.05 level (2-tailed)
\end{tabular}

*** Significant at the 0.01 level (2-tailed); ** Significant at the 0.05 level (2-tailed)

This study applied ANCOVA to examine the effects of pop music and actors/actresses on product awareness, cultural awareness, perception of suitability of the cultural wave for respondents' social class, strength of attitudes toward acculturation, overall attitudes, actual behavior, and behavior change. Table 3 shows the results of hypotheses 5a-d and 6a-d (hypotheses 5a-d for perception of pop music and 6a-d for perception of actors/actresses). 
As shown in Table 3, the effects of both product and cultural awareness on overall attitudes are significantly affected by the effects of pop music at $\alpha=.01(F$-value $=11.454$ and 13.627) and actor/actress at $\alpha=.01(F$-value $=12.762$ and 14.459), while the effects of perception of the suitability of the cultural wave for the respondents' social class and the strength of attitudes toward acculturation on overall attitudes are not affected by the effects of pop-music or actor/actress. Therefore, hypotheses 5a-b and 6a-b are accepted, while 5c-d and $6 c-d$ are rejected.

Table 3: Summary of the Effects of Product, Culture Awareness, Perception on Class, and Strength of Attitudes toward Acculturation on Overall Attitudes with Side Effects

\begin{tabular}{|l|c|c|}
\hline \multirow{2}{*}{ Effects based on Perception on Pop Music and Actor/Actress } & \multicolumn{2}{|c|}{ F-value (Sig) } \\
\cline { 2 - 3 } Effects of Product Awareness on Overall Attitudes & Effects of Pop Music & Effects of Actor/Actress \\
\hline Effects of Culture Awareness on Overall Attitudes & $11.454\left(0.00^{* * *)}\right.$ & $12.762\left(0.00^{* * *}\right)$ \\
\hline Effects of Perception on Class on Overall Attitudes & $13.627\left(0.00^{* * *}\right)$ & $14.459\left(0.00^{* * *}\right)$ \\
\hline Effects of Strength of Attitudes toward Acculturation on Overall Attitudes & $2.417(0.122)$ & $1.341(0.249)$ \\
\hline
\end{tabular}

*** Significant at the 0.01 level (2-tailed); ${ }^{* *}$ Significant at the 0.05 level (2-tailed); * Significant at the 0.1 level (2-tailed)

\section{CONCLUSION}

The purpose of this study was to examine the impact of the cultural wave on the acceptance of Korean culture and products in addition to overall attitude, behavior, and behavior change. This study suggests that the influences of the cultural wave on people's preferences can be explained by the engagement of people with the cultural wave itself. By considering the media impact, this study has examined how the proposed factors affect overall attitudes and behavior changes. This study in particular has explored the following relationships: 1) how product awareness via media affects people's overall attitudes, 2) how cultural awareness via media affects people's overall attitudes, 3) how the perception of suitability of the cultural wave for respondents' social class via media affects people's overall attitudes, and 4) how the strength of attitudes toward acculturation affect people's overall attitude. Furthermore, this study investigated the impacts of overall attitude on actual behavior and behavior change. It found that the effects of product and cultural awareness are significant and that pop music and actor/actress also have significant effects on overall attitudes.

Theoretically, this study contributes to the understanding of media impact on the attitude and behavior. Theories and models that support the impact of media are applicable, even in the global environment. The impacts of the media and technology have been described as cultural globalization about forming and reforming cultural values, identities and perception. Moreover, cross culture consumer behavior theory suggests that cultural impact is the largest factor in influencing consumer behavior, not only in material matters (food, clothes, etc.) but also involving abstract elements (value, behavior, etc.). This phenomenon is also supported by cultivation and social action theory, which considers the relationship between media and audience perception and behavior. This study supports the validity of those theories, in that the more people are engaged in the cultural wave being spread by the media, especially TV, the more people are likely to purchase culturally conditioned products or learn about the culture, which in turn can affect their overall attitude and behavior. Another significant finding is that peoples' perceptions of products associated with the cultural wave are positively related to their willingness to purchase products associated with the country of origin of the product. This supports the country of origin (COO) effect theory where the acceptance of the product on the market is affected by consumers' attitudes towards the country that produces the product. Further, this phenomenon can also be explained by the elaboration likelihood model where there are two basic routes of persuasion - high or low involvement. This study supports the view that consumers are likely using low involvement (attractive sources) in dealing with the cultural wave.

As for culture awareness, the more people perceive the Korean wave positively, the more likely they are to learn about Korean culture. On the other hand, there is no significant correlation between people in higher social classes having positive image of the Korean wave changing their attitudes. Also, there is no correlation between people who are positive toward acculturation and attitude change.

Regarding the relation of perception of Korean-pop/soundtrack and the affection to actor and actress to the overall attitude, it showed different results. This study revealed that the majority of the respondents were affected by K-pop/soundtrack and Korean celebrities and that the Korean wave affected their perceptions of products and 
culture and their willingness to change their attitudes. However, there was no significant correlation between Korean-pop/soundtracks and Korean celebrities with perception of the suitability of the cultural wave for respondents' class position and strength of attitude toward acculturation.

In conclusion, the results of this study are 1) Korean products and cultural awareness affect the willingness of Indonesian people to change their attitudes and behavior, 2) the Korean wave influences people in buying Korean products and developing cultural awareness through Korean celebrities and Korean-pop/soundtracks, 3) there is no positive relations between perceptions of the Korean wave related to social class or concerning changing attitudes, and 4) there is also no positive relation between the strength of people's attitudes toward acculturation and changes in their attitudes and/or behavior.

The results of this study also provide some contributions for practitioners. First, for business stakeholders, the Korean wave has generated numerous business values and opportunities. Therefore, businesses should develop more products featuring Korean wave values using better methods and management tools, like using more Korean celebrities to advertise their products or enhancing styles of Korean pop in the entertainment business. Second, for the Korean government, based on the results of this study, the effects of the Korean wave have developed the Korean brand and culture; therefore, the government needs to put more effort into maintaining the role and popularity of the Korean wave. At the same time, government also needs to keep an eye on the development and preservation of Korean culture and product. Thus, by making this effort, it may be able to increase business and government revenue and improve both the country's image and its position in the world, while also developing international relations between countries.

The study has several implications. First, the survey was conducted only in one city, where entertainment is quite easy to access. Hence, there may have been a quite different result if it was conducted in a place where access to entertainment was more difficult. Second, Jakarta is not the only big city that has been influenced by the Korean Wave; there are several other big cities in Indonesia. Third, the age range of the sample was quite narrow. This may not accurately represent the Indonesian people as a whole. Therefore, future studies should focus more on the personal characteristics and backgrounds of ethnic groups. A further study with a larger sample to include more variety of places, age groups, ethnic groups, and personal characteristics, would be a good development of the current study. Although this study applies multivariate statistics, further studies might consider the measurement of a cause-and-effect relationship. Finally, further research might consider applications to other environments, such as cross-cultures/countries, for generalization.

\section{AUTHOR INFORMATION}

Rahmiati Lita received master degree from the KDI School of Public Policy and Management. E-mail: lita_manan@yahoo.com

Dr. Yoon C. Cho is Associate Professor at the KDI School of Public Policy and Management, global school, located in Seoul. She published research papers in the various academic journals such as Journal of Business Research (JBR), Advances in Consumer Research (ACR), Journal of Business \& Economics Research (JBER), etc. E-mail: ycho@kdischool.ac.kr (Corresponding author)

\section{REFERENCES}

1. Ajzen, Icek and Fishbein, Martin (1980), Understanding Attitudes and Predicting Social Behavior, New Jersey: Prentice -Hall

2. Amnuaychai, Montira Tada (2006), Korean Media Industry and Its Cultural Marketing Strategy of K-Pop”, Asia Culture Forum

3. Arnould, Eric J. and Thompson, Craig J. (2005), "Consumer Culture Theory (CCT): Twenty Years of Research," Journal of Consumer Behavior, March.

4. Belch, Geroge E. and Belch, Michael A. (2007), Advertising and Promotion: An Integrated Marketing Communications Perspective, McGraw-Hill, Irwin. 
5. Categora, Philip, R., Gilly, Mary C. and Graham, John L. (2011), International Marketing, $15^{\text {th }}$ edition, McGraw-Hill Irwin.

6. Chan, Fanny Fong Yee (2012), "Product Placement and its Effectiveness: A Systematic Review and Propositions for Future Research," The Marketing Review, 12, 1, pp.39-60.

7. Cho, Y. (2011), "Analysis of Customer Dissatisfaction toward Perishable Grocery Goods," Journal of Business Research, Vol. 64, pp.1245-1250.

8. Class, Maria Lopez, Castro, Felipe Gonzales, Ramirez, Amelie G. (2011), "Conceptions of Acculturation: A Review and Statement of Critical Issues”, Journal of Science and Medicine, No. 72, pp.1555-1562.

9. Cooper, Donald R and Schindler, Pamela S (2008), Business Research Method, $10^{\text {th }}$ ed., Boston: McGraw Hill Education

10. Ewoldsen, Beverly R, Davies, John, and Ewoldsen, David R. R (2004), "Implications of the Mental Models Approach for Cultivation Theory". The European Journal of Communication Research, Vol. 29, pp.345363.

11. Fishbein, M. and Ajzen, I. (1975), Belief, Attitude, Intention, and Behavior: An Introduction to Theory and Research, Reading, MA: Addition-Wesley.

12. Gerbner. G. (1969), "Toward Cultural Indicators: The Analysis of Mass Mediated Message Systems," AV Communication Review, 17, pp.137-148.

13. Gerbner, G., Gross, L., Morgan, M., \& Signorielli, N. (1994), "Growing up with Television: The Cultivation Perspective. In J. Bryant \& D. Zillmann (Eds.), Media Effects: Advances in Theory and Research, pp.17-41., Hillsdales, NJ: Erlbaum.

14. Gregorio, Federico de. And Sung, Yongjun (2010), "Understanding Attitudes toward and Behaviors in Response to Product Placement," Journal of Advertising, 39, 1, pp.83-96.

15. Heryanto, Ariel (2010), "The Look of Love" in Pop Culture Formation Across East Asia, ed. Doobo Shim and others, Korea: Jimoondang.

16. Huat, Chua Beng (2010), "Korean Pop Culture," Malaysian Journal of Media Studies, Vol. 12, No. 1.

17. Jeffres, Leo W., Atkin, David, J., and Neuendorf, Kimberly A. (2001), "Expanding the Range of Dependent Measures in Mainstreaming and Cultivation Analysis," Communication Research Reports, Fall, pp.408417.

18. Kang, Chul Geun, (2011) "Making of Hallyu and Its Future”, Korean Culture and Korean Wave Workshop, Han On Seminar.

19. Kim, D. K., Singhal, A., Hanaki, T., Dunn, J., Chitnis, K., \& Han, M.W. (2009). "Television Drama, Narrative Engagement and Audience Buying Behavior: The Effects of Winter Sonata in Japan”. The International Communication Gazette, vol. 71(7): 1-6

20. Ko, Jeongmin (2010), "Trends and effects of Korean wave" in Pop Culture Formation Across East Asia, ed. Doobo Shim and others, Korea: Jimoondang.

21. Kotler, Philip and Lee, Nancy R. (2008), Social Marketing: Influencing Behaviors for Good, 3rd edition, Sage Publications, Inc.

22. Lee, Sue Jin (2011), "The Korean Wave: The Seoul of Asia," The Elon Journal of Undergraduate Research in Communications, Vol.2, No.1, Spring, pp.85-93.

23. Mariani, Evi (2008), "Delicious Boys Leas Hallyu in Indonesia" in Korean Wave, ed. The Korea Herald, Paju: Jimoondang.

24. Manrai, Lalita A and Manrai, Ajay K. (2011), "Cross Culture and Cross-National Consumer Research in the Global Economy of the Twenty-First Century”, Journal of International Consumer Marketing, 23 pp.167180.

25. Morgan, M and Shanahan, J (2010) 'The State of Cultivation', Journal of Broadcasting and Electronic Media 54:337-355.

26. Mooij, Marieke K. de (2004) Consumer Behavior and Culture: Consequences for Global Marketing and Advertising, California: Sage Publication, Inc

27. Nabi, R. L. and Sullivan, J. L. (2001), "Does Television Viewing relate to Engagement in Protective Action against Crime? A Cultivation Analysis from a Theory of Reasoned Action Perspective," Communication Research, Vol. 28, Issue 6, pp.802-825.

28. Nopiyanti, (2011, October 4), "Korean Festival' Shakes Gandaria City," Retrieved from http://www.Tnol.co.id 
29. Peart, K. (2010) "Reason \& Respect: Civil Disclosure in a Global Context, Reason and Respect," Retrieved, November, from reasonandrespct.rwu.edu/journal/index/php/2009/02/07.

30. Potter, W. J. (1988), "Perceived Reality in Television Effects Research," Journal of Broadcasting and Electronic Media, 32, pp.23-41.

31. Ravina, M. (2010), "Introduction: Conceptualizing the Korean Wave: Southeast Review of Asian Studies," Magazine Back Issues \& Reference Articles, http://findarticles.com/p/articles/mi_7066/is_31/ai_n45060645.

32. Reeves, B., Chafee, S., and Tims, A. (1982), Social Cognition and Mass Communication Research, in M. E. Roloff \& C. R. Berger (Eds.), Social Cognition and Mass Communication, pp.287-326, Newbury Park, CA: Sage.

33. Seo, Sunhee, Phillips, Woomi Jo, Jang, Junghee, Kim, Kawon (2012), "The Effects of Acculturation and Uncertainty Avoidance on Foreign Resident Choice for Korean Foods", International Journal of Hospitality Management, No. 31: 916-927

34. Shapiro, Michael A. and Chock, Makana T. (2003), "Psychological Processes in Perceiving Reality," Media Psychology, 5, pp.163-198.

35. Shrum, L. J. and Bischak, Valerie Darmanin (2001), "Mainstreaming, Resonance, and Impersonal Impact: Testing Moderators of the Cultivation Effect for Estimates of Crime Risk," Human Communication Research, Vol. 27, No. 2, April, pp.187-215.

36. Shrum, L. J. (2009), "Media Consumption and Perceptions of Social Reality: Effects and Underlying Processes," in J. Bryant \& M. D. Oliver (Eds.), Media effects: Advances in theory and research, 3rd ed., pp. 51-73, New York.

37. Triandis, Harry C. (1994), Culture and Social Behavior, McGraw-Hill.

38. Wang, Shiaw Ling, (2005) "Comparing Three Theories in Predicting Reproductive Health Behavior in Adolescent Women with Diabetes" Ph.D. diss., University of Pittsburgh.

39. Zikmund, William G. (2010), Business Research Methodology, $8^{\text {th }}$ ed., Mason OH: South Western Cengage Learning

\section{OTHER RESOURCES}

1. Kamil, Ati (2012, January 15), “Gelombang Korea” Menerjang Dunia, Kompas, Retrieved from http://entertainment.kompas.com.

2. Naripan, Adhi.L, (2011, August 6), The Green Robot Crushed Pasific Place. Retrieved from www.icetrack.blogspot.com. 